\title{
Estimation of Genetic Diversity among Genotypes of Fodder Oat based on Principal Component Analysis
}

\author{
Monica Jyoti Kujur*, A. K. Mehta, S. K. Bilaiya and Prakarti Patil
}

Dept. of Plant Breeding and Genetics, College of Agriculture, JNKVV, Jabalpur (482 004), India

\section{Corresponding Author}

Monica Jyoti Kujur

e-mail: monikajyotikujur@gmail.com
Article History

Article ID: 3 C0269

Received in $28^{\text {th }}$ September, 2017

Received in revised form $25^{\text {th }}$ November, 2017

Accepted in final form $5^{\text {th }}$ December, 2017

\begin{abstract}
The present investigation was planned to assess genetic diversity for fodder yield and yield contributing traits in fifty oat genotypes including two checks from different geographic regions and were evaluated in randomized block design with three replications at Seed Breeding Farm, Department of Plant Breeding and Genetics, College of Agriculture JNKVV Jabalpur during rabi, 2014. The traits were studied through principal component analysis (PCA). Out of eighteen, ten principal components (PC1 to PC10) exhibited more than 0.5 eigen values and showed about $89.52 \%$ total variability among the characters studied. PC1 accounts mostly for yield related traits like penultimate leaf area, panicle weight, axis branch number, spikelets panicle ${ }^{-1}$, florets panicle ${ }^{-1}$ and grain yield. The combined variation among these traits was $23.342 \%$. PC2 was contributed by both physiological and yield related traits which are days to $50 \%$ flowering, days to flower initiation, number of leaves plant ${ }^{-1}$ dry matter yield and grain fodder yield. PC3 include trait i.e. plant height. PC4 includes trait axis length. PC5 include by physiological trait i.e. days to maturity. PC6 include yield trait 1000 seed weight. On the basis of PC score germplasm like HFO25, IC372418, IC372413 and JHO-11 can be used for development of new oat varieties. These information would be very useful to select potentially breeding lines for future oat improvement program.
\end{abstract}

Keywords: PCA, fodder, oat, dual purpose oat, green fodder yield, genetic diversity

\section{Introduction}

Oat (Avena sativa L.) is one of the most important cereal fodder crops of rabi season in North, Central and West Zone of the country. It is widely cultivated for use as food, feed and fodder. They are fast growing and produces significant amount of fresh fodder within short period (60-70 days) with adequate nutritional value (Bilal et al., 2017). In many parts of the world, oat is grown for grain as well as straw for bedding, hay, haylage, silage and chaff. Its grain makes a good feed particularly for horses, sheep and poultry. Oat is one of the most important cereal fodder crop having an excellent growth habit, quick cutting recovery, palatable, succulent and nutritious herbage. In recent years, with the advent of exaggerated dairy industry in our country, oat has fascinated the attention of breeders for its improvement due to its nutritious quality fodder for livestock and its grains as animal feed with high net energy gains (Ruwali et al., 2013). The nutritive value of oat forage is high and dry matter digestibility is in excess of $75 \%$ when fed to dairy cattle (Burgess et al., 1972). It provides soft and palatable fodder rich in crude protein (10-12\%) and protein content of the hull-less oat kernel (groat) ranges from 12-24\%, the highest among cereals
(Lasztity, 1999). It also contains $20 \%$ dry matter, $10 \%$ crude protein, $91 \%$ organic matter (DM basis) (Gupta et al., 2004). The chemical composition of green fodder varies with the stage of harvest. Oat produces an abundance of excellent fodder at the time when other succulent better quality fodders are scarce and cannot be cut/grazed as a green feed, hay or silage crop. It forms an excellent combination when fed along with other cold season legumes, like berseem, Lucerne, senji, shaftal, pea and vetch. The total area covered under oat cultivation in the country is about 500000 ha. The crop occupies a maximum area in Uttar Pradesh (34\%), followed by Punjab (20\%), Bihar (16\%), Haryana (9\%) and Madhya Pradesh (6\%) (Panday et al., 2011).

\section{Materials and Methods}

In the present study, fifty germplasm (Table 1 ) were grown in randomized complete block design. The experiment was carried out at the Seed Breeding Farm, Department of Plant Breeding \& Genetics, College of Agriculture JNKVV Jabalpur. The sowing of the experimental material was done on $23^{\text {rd }}$ November 2014. Each plot was maintained of size $3 \times 0.6 \mathrm{~m}^{2}$ and having two rows for each treatment in each replication. 


\begin{tabular}{|c|c|c|c|c|c|}
\hline SI. No. & Germplasm & Source & SI.No. & Germplasm & Source \\
\hline 1. & IC372442 & IGFRI, Jhansi & 26. & HFO-2 & HAU- Hissar \\
\hline 2. & JHO-3 & IGFRI, Jhansi & 27. & HFO-3 & HAU- Hissar \\
\hline 3. & IC372414 & IGFRI, Jhansi & 28. & HFO-4 & HAU- Hissar \\
\hline 4. & IC372416 & IGFRI, Jhansi & 29. & HFO-5 & HAU- Hissar \\
\hline 5. & IC372438 & IGFRI, Jhansi & 30. & PI486164 & USA \\
\hline 6. & IC372443 & IGFRI, Jhansi & 31. & PI498912 & USA \\
\hline 7. & IC372437 & IGFRI, Jhansi & 32. & PI486862 & USA \\
\hline 8. & IC372452 & IGFRI, Jhansi & 33. & EC209638 & USA \\
\hline 9. & JHO-10 & IGFRI, Jhansi & 34. & EC209568 & USA \\
\hline 10. & JHO-11 & IGFRI, Jhansi & 35. & EC209341 & USA \\
\hline 11. & IC372421 & IGFRI, Jhansi & 36. & Cl9771 & USA \\
\hline 12. & IC372445 & IGFRI, Jhansi & 37. & BGP-33 & Brazil \\
\hline 13. & IC372461 & IGFRI, Jhansi & 38. & BGP-37 & Brazil \\
\hline 14. & IC372415 & IGFRI, Jhansi & 39. & BGP-48 & Brazil \\
\hline 15. & IC372425 & IGFRI, Jhansi & 40. & BGP-4 & Brazil \\
\hline 16. & IC372423 & IGFRI, Jhansi & 41. & BGP13 & Brazil \\
\hline 17. & JHO-18 & IGFRI, Jhansi & 42. & HFO-18 & HAU- Hissar \\
\hline 18. & IC372432 & IGFRI, Jhansi & 43. & HFO-19 & HAU- Hissar \\
\hline 19. & IC372422 & IGFRI, Jhansi & 44. & PA2672 & GBPUAT-Pantnagar \\
\hline 20. & IC372413 & IGFRI, Jhansi & 45. & PA2857 & GBPUAT-Pantnagar \\
\hline 21. & IC372418 & IGFRI, Jhansi & 46. & PA3562 & GBPUAT-Pantnagar \\
\hline 22. & IC372428 & IGFRI, Jhansi & 47. & HFO-24 & GBPUAT-Pantnagar \\
\hline 23. & IC372431 & IGFRI, Jhansi & 48. & HFO-25 & GBPUAT-Pantnagar \\
\hline 24. & IC372419 & IGFRI, Jhansi & 49. & KENT & CHECK \\
\hline 25. & HFO-1 & HAU- Hissar & 50. & JO-1 & CHECK \\
\hline
\end{tabular}

The row length was kept at $3 \mathrm{~m}$, distance between rows was kept at $30 \mathrm{~cm}$ and plant to plant was $5 \mathrm{~cm}$. Five competitive plants were randomly selected and tagged in each plot per replication for recording observation on eight fodder yielding characters, namely, plant height, number of leaves plant ${ }^{-1}$, penultimate leaf area, tillers meter ${ }^{-1}$ row, internodal length, stem girth, dry matter yield and green fodder yield, and fifteen grain yield contributing characters, namely, days to $50 \%$ flowering, days to maturity, plant height, number of leaves plant $^{-1}$, penultimate leaf area, tillers meter ${ }^{-1}$ row, internodal length, panicle weight, axis length, spikelets panicle ${ }^{-1}$, florets panicle ${ }^{-1}$, dry matter yield, 1000 grain weight, green fodder yield and grain yield. However, days to $50 \%$ flowering were recorded on plot basis. Principal component analysis was also used to determine genetic variability for these traits. Genotypic means were used for the PCA with respect to each trait. The mean values of the observations were analysed using INDOSTAT software.

\section{Results and Discussion}

Principal component analysis, basically a well-known data reduction technique, initially floated by Pearson (1901) and later developed by Hotelling (1933), offers solution to this complex problem by transforming the original set of variables into smaller set of linear combinations that account for most of the variability of the original data set. The objective of principal component analysis is to identify the minimum number of components, which can explain maximum variability out of the total variability (Anderson, 1972 and Morrison, 1982) and also to rank germplasms on the basis of PC scores.

The first principal component i.e. PC1 accounted for maximum proportion of total variability in the set of all variables and remaining components accounted for progressively lesser and lesser amount of variation. The first principal component accounted for maximum variability i.e., $23.342 \%$ which 
reduced gradually to $2.831 \%$ in ten principal components. The first ten principal components having eigen values greater than 0.5 altogether explained $89.52 \%$ (Table 2) of the total variation.Screen plot (Figure 1) explained the percentage of variance associated with each principal component obtained by drawing a graph between eigen values and principal component numbers. PC1 showed $23.342 \%$ variability with eigen value 4.201 which then declined gradually. Semi curve line is obtained after ten PC tended to become straight with little variance observed in each PC. The maximum variation was observed in PC1 in comparison to other nine PCs. So, selection of lines from this PC is useful.

Table 2: Eigen values, \% variance and cumulative eigen values of oat germplasm

\begin{tabular}{lcccc}
\hline Character & PC & $\begin{array}{c}\text { Eigen } \\
\text { value }\end{array}$ & $\begin{array}{c}\% \\
\text { variability }\end{array}$ & $\begin{array}{c}\text { Cumulative } \\
\%\end{array}$ \\
\hline DFF & PC1 & 4.201 & 23.342 & 23.342 \\
DM & PC2 & 3.104 & 17.247 & 40.588 \\
DFI & PC3 & 1.830 & 10.167 & 50.756 \\
PH & PC4 & 1.698 & 9.434 & 60.189 \\
NLPP & PC5 & 1.340 & 7.446 & 67.635 \\
PLA & PC6 & 1.121 & 6.228 & 73.864 \\
TPMR & PC7 & 0.928 & 5.156 & 79.020 \\
IL & PC8 & 0.807 & 4.482 & 83.502 \\
PL & PC9 & 0.575 & 3.194 & 86.696 \\
PW & PC10 & 0.510 & 2.831 & 89.527 \\
AL & PC11 & 0.471 & 2.617 & 92.143 \\
ABN & PC12 & 0.397 & 2.204 & 94.347 \\
SPP & PC13 & 0.335 & 1.862 & 96.209 \\
FPP & PC14 & 0.236 & 1.309 & 97.518 \\
DMY & PC15 & 0.213 & 1.181 & 98.699 \\
1000SW & PC16 & 0.108 & 0.598 & 99.297 \\
GY & PC17 & 0.084 & 0.468 & 99.765 \\
GFY & PC18 & 0.042 & 0.235 & 100.000 \\
\hline DFF: Days & $50 \%$ & &
\end{tabular}

DFF: Days to 50\% flowering; DM: Dry matter; DFI: Days to flower initiation; PH: Plant height; NLPP: Number of Leaves plant ${ }^{-1}$; PLA: Penultimate leaf area; DTM: Days to maturity, TPMR: Tillers per meter row; IL: Internodal length; PL: Peduncle length; PW: Panicle weight; AL: Axis length; $A B N$ : Axis branch number; SPP: Spikelet panicle ${ }^{-1}$; FPP: Florets panicle ${ }^{-1}$; DMY: Dry matter yield; 1000 SW: 1000 seed weight; GFY: Green fodder yield; SY: Grain yield

Rotated component matrix depicted in Table 3 revealed that the PC1 which accounted for the highest variability $23.342 \%$. PC1 accounts mostly for yield related traitslike penultimate leaf area, panicle weight, axis branch number, spikeles panicle ${ }^{-1}$, florets panicle ${ }^{-1}$ and grain yield. PC2 was

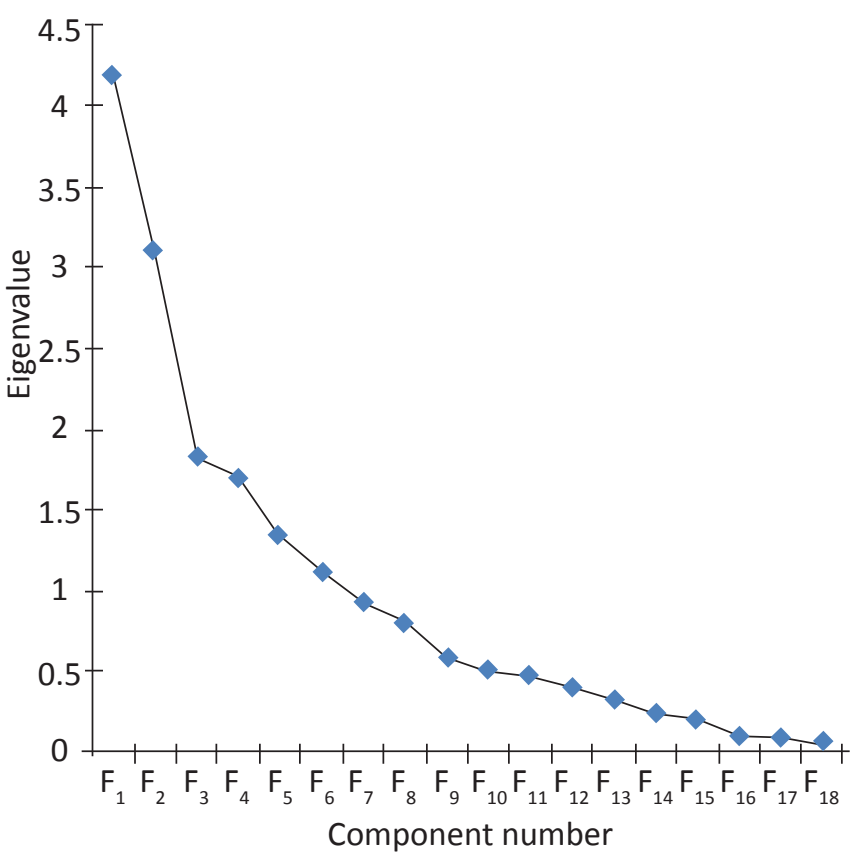

Figure 1: screen plot

Table 3: Rotated component matrix* for 18 variables of oat germplasm

\begin{tabular}{lllllll}
\hline TRAITS & PC1 & PC2 & PC3 & PC4 & PC5 & PC6 \\
\hline DFF & -0.209 & 0.681 & 0.094 & -0.284 & 0.102 & 0.205 \\
DM & 0.019 & 0.050 & 0.243 & -0.038 & 0.841 & -0.262 \\
DFI & -0.262 & 0.568 & 0.194 & 0.068 & -0.166 & 0.403 \\
PH & 0.362 & 0.221 & 0.671 & -0.351 & -0.028 & 0.101 \\
NLPP & 0.280 & 0.699 & -0.017 & -0.218 & -0.317 & -0.202 \\
PLA & 0.624 & 0.369 & 0.400 & 0.139 & -0.051 & 0.017 \\
TPM & 0.387 & 0.329 & -0.555 & -0.198 & -0.308 & 0.057 \\
IL & 0.246 & 0.279 & 0.461 & 0.451 & -0.270 & -0.405 \\
PL & -0.105 & -0.106 & -0.041 & -0.623 & -0.333 & -0.447 \\
PW & 0.829 & -0.128 & -0.147 & -0.080 & 0.117 & 0.090 \\
AL & 0.239 & 0.238 & 0.165 & 0.696 & -0.152 & -0.033 \\
ABN & 0.633 & 0.050 & 0.189 & -0.218 & 0.129 & -0.282 \\
SPP & 0.701 & -0.176 & -0.247 & 0.217 & -0.012 & 0.075 \\
FPP & 0.807 & -0.261 & -0.261 & 0.222 & -0.001 & 0.144 \\
DMY & -0.100 & 0.807 & -0.410 & 0.111 & 0.197 & -0.112 \\
1000SW & 0.484 & 0.147 & 0.190 & -0.304 & 0.125 & 0.513 \\
GY & 0.850 & 0.031 & -0.182 & -0.186 & 0.122 & -0.160 \\
GFY & -0.115 & 0.772 & -0.376 & 0.131 & 0.300 & -0.117 \\
\hline Rotation Metho Varmaxw & W &
\end{tabular}

Rotation Method: Varimax with Kaiser Normalization; *Rotation converged in 14 iterations; Maximum value in each PC has been highlighted

contributed by both physiological and yield related traits which are days to $50 \%$ flowering, days to flower initiation, 
number of leaves plant ${ }^{-1}$, dry matter yield and grain fodder yield. PC3 include trait i.e. plant height. PC4 includes trait axis length. PC5 include by physiological trait i.e. days to maturity. PC6 include yield trait 1000 seed weight. These results were in close correspondence with Tanoli et al. (2016) who revealed that plant height, leaf length, leaf width, number of tillers plant $^{-1}$, number of leaves tiller ${ }^{-1}$, days to maturity, spike length, number of grains spikelet ${ }^{-1}$, number of spikelets spike ${ }^{-1}$ and seed yield plant ${ }^{-1}$ are important principal component.

\section{Conclusion}

PC1 and PC6 were mostly related to yield traits. PC2, PC3, PC4 and PC5 were mostly related to physiological traits. As PC1 was constituted by most of the yield attributing traits, an intensive selection procedure can be designed to bring out rapid improvement of dependent traits i.e., yield by selecting the lines from PC1. Maximum positive value was recorded in HFO-25 (2.822), IC372418 (2.736), IC372413 (2.241) and JHO-11(1.957) HFO-25 (2.822) and was found to be common in PC1, PC 2 and PC5, IC372418 (2.736) found to be common in PC1, PC2 and PC4, IC372413 (2.241) found to be common in PC1, PC2 and PC6, while JHO-11 (1.957) presenting their contribution in PC1, PC3 and PC5. On the basis of PC score which is present in different germplasm like HFO-25, IC372418, IC372413 and JHO-11 can be used for development of new varieties in breeding programmes.

\section{References}

Anderson, T.W., 1972. An introduction to multivariate analysis. Wiley Eastem Pvt. Ltd., New Delhi

Bilal, M., Ayub, M., Tariq, M., Tahir, M., Nadeem, M., 2017. Dry matter yield and forage quality traits of oat (Avena sativa L.) under integrative use of microbial and synthetic source of nitrogen. Journal of the Saudi Society of Agricultural Sciences 16(3), 236-241.

Burgess, P.L., Grant, E.A., Nickolson, J.W.G., 1972. Feeding of "forage" oats. Canadian Journal of Animal Science $52,448-450$.

Lasztity, R., 1999. The Chemistry of Cereal Proteins. Akademiai Kiado. ISBN 9780849327636.

Gupta, B.K., Bhardwaj, B.L., Ahuja, A., 2004. Nutritive Value of Fodder Crops of Punjab. Punjab Agricultural University, Ludhiana.

Hotelling, H., 1933. Analysis of complex statistical variables into principal components. Journal of Educational Psychology 24, 417.

Morrison, D.E., 1982. Multivariate Statistical Methods ( $2{ }^{\text {nd }} E d$. $4^{\text {th }}$ Print, 1978). McGraw Hill Kogakusta Ltd.

Pandey, K.C., Roy, A.K., 2011. Forage Crops Varieties. Indian Grassland and Fodder Research Institute, Jhansi, 16.

Pearson, K., 1901. On lines and Planes of Closest Fit to Systems of Points in Space. Philosophical Magazine 2, 559.

Ruwali, Y., Singh, K., Kumar, S., Kumar, L., 2013. Molecular Diversity Analysis in Selected Fodder and Dual Purpose Oat (Avena sativa L.) Genotypes by Using Random Amplified Polymorphic DNA (RAPD). African Journal of Biotechnology 12(22), 3425-29.

Tanoli, M.T.Z., Ali, S., Khan, N., Rabbani, M.K., Khan, S.A., Khan, S.M., Naveed, K., Arif, M., 2016. Estimation of Genetic Diversity among Oat Genotypes through Agro-morphological Traits. International Journal of Biosciences 9(5), 35-44. 